\title{
BMJ Open Evaluation of a shared decision-making intervention for dialysis choice at four Danish hospitals: a qualitative study of patient perspective
}

Jeanette Finderup (D) , ${ }^{1,2}$ Jens Dam Jensen, ${ }^{1,2}$ Kirsten Lomborg ${ }^{2}$

To cite: Finderup J, Dam Jensen J, Lomborg K. Evaluation of a shared decisionmaking intervention for dialysis choice at four Danish hospitals: a qualitative study of patient perspective. BMJ Open 2019;9:e029090. doi:10.1136/ bmjopen-2019-029090

- Prepublication history and additional material for this paper are available online. To view these files, please visit the journal online (http://dx.doi org/10.1136/bmjopen-2019029090).

Received 11 January 2019 Revised 18 September 2019 Accepted 19 September 2019

Check for updates

(C) Author(s) (or their employer(s)) 2019. Re-use permitted under CC BY-NC. No commercial re-use. See rights and permissions. Published by BMJ.

${ }^{1}$ Renal Medicine, Aarhus University Hospital, Aarhus N, Denmark

${ }^{2}$ Clinical Medicine, Aarhus University, Aarhus N, Denmark

Correspondence to Dr Jeanette Finderup; jeajee@rm.dk

\section{ABSTRACT}

Objective To evaluate the 'Shared Decision-making and Dialysis Choice' (SDM-DC) intervention with regard to patients' experience and involvement.

Design Semistructured individual interviews and systematic text condensation for data analysis.

Setting The SDM-DC intervention was implemented and evaluated at four different hospitals in Denmark.

Participants A total of 348 patients had received the SDM-DC intervention, and of these 29 patients were interviewed.

Interventions SDM-DC was designed for patients facing a choice of dialysis modality. The available modalities were haemodialysis and peritoneal dialysis, either performed by patients on their own or with help from a healthcare professional. The intervention was tailored to individual patients and consisted of three meetings with a dialysis coordinator who introduced a patient decision aid named 'Dialysis Choice' to the patient.

Findings The following were the four main findings: the decision was experienced as being the patient's own; the meetings contributed to the decision process; 'Dialysis Choice' contributed to the decision process; and the decision process was experienced as being iterative. Conclusions The patients experienced SDM-DC as involving them in their choice of dialysis modality. Due to the iterative properties of the decision-making process, a shared decision-making intervention for dialysis choice has to be adapted to the needs of individual patients. The active mechanisms of the meetings with the dialysis coordinator were (1) questions to and from the patient, and (2) the dialysis coordinator providing accurate information about the options. The overview of options and the value clarification tool in the decision aid were particularly helpful in establishing a decision-making process based on informed preferences.

\section{INTRODUCTION}

Patients with kidney failure must make a decision regarding dialysis modality, choosing either haemodialysis or peritoneal dialysis. Based on research, one modality is not uniquely better than the other. ${ }^{1-3}$ In order to offer the modality best suited to each patient's everyday lifestyle, international guidelines recommend involving the individual patient
Strengths and limitations of this study

- Data richness was established by interviewing 29 patients that lasted on average $50 \mathrm{~min}$, with an information load of 23 normal pages on average.

- Shared Decision-making and Dialysis Choice seems to be the first intervention based on the 'three-talk model', which is a well-cited shared decision-making model.

- The whole research process has involved patients and healthcare professionals providing the intervention.

- The research included Caucasian patients only born in Denmark, and the findings are therefore limited to ethnic Danish patients.

- One of the developers of the intervention performed the interviews, but this challenge has been addressed in several ways.

in the decision-making process, thus basing the decision on the patient's preferences. ${ }^{3}$ However, patient involvement does not always occur. ${ }^{4-6}$ For example, two studies from the USA showed that only $13 \%$ of patients experienced the decision process as shared decision-making $(\mathrm{SDM})^{7}$ and that patients over the age of 65 years did not experience the decision as a shared one. ${ }^{8}$ More recent studies indicate improvements in this area. A study from the UK that included routine measures of patient involvement at 27 different nephrology departments found that $69 \%$ of patients experienced SDM. ${ }^{9}$

Based on SDM for dialysis choice, we developed and pilot-tested an intervention called 'Shared Decision-making and Dialysis Choice' (SDM-DC) with the purpose of involving patients and their relatives in the decision-making process. ${ }^{10}$ In this article, we document patients' perspectives on using the SDM-DC intervention at four different hospitals in Denmark. 


\section{BACKGROUND}

A study of patient involvement in dialysis choice suggested that SDM could improve patients' experiences of involvement in the decision. ${ }^{11}$ A Cochrane review indicated that an intervention based on SDM and supported by a patient decision aid (PDA) increased patients' experience of involvement. ${ }^{12}$ Another Cochrane review focusing on PDAs showed middle-quality evidence that PDAs increase the proportion of people who are active in decision-making. ${ }^{13}$

The SDM-DC intervention was developed in 2015 and then described and pilot-tested. ${ }^{10}$ It includes a PDA, named 'Dialysis Choice', and is designed for patients with kidney failure who must make a decision regarding their future dialysis mode: haemodialysis or peritoneal dialysis. Both options may be performed by patients on their own or with help from a healthcare professional. SDM-DC is structured according to the "three-talk model' ${ }^{14}$ and consists of three meetings between the patient and his or her relative(s) and a dialysis coordinator. The dialysis coordinators have been trained to deliver the intervention using tailoring ${ }^{15}$ based on a decision needs assessment and using three different communication skills: mirroring, active listening and value clarification. ${ }^{16-18}$ The PDA is designed to be used both at and between the meetings with individual patients and relatives who may be joining them. Two videos with personal stories are available to be shown and discussed at the meetings if the patient needs to hear a personal story. Patients and healthcare professionals have been involved in the development of the intervention and the PDA. ${ }^{19}$ The decision aid is based on a systematic literature search where possible. Further, the PDA is inspired by three other decision aids. ${ }^{20-22}$ The PDA is in paper format. It has been accepted for the A to Z Inventory of Decision Aids (https://decisionaid.ohri. $\mathrm{ca} /$ ) and assessed according to the International Patient Decision Aids Standards. ${ }^{23}$ The PDA consists of a set of tools: a decision map, an overview of uraemic symptoms, an overview of options and the Ottawa Personal Decision Guide. ${ }^{24}{ }^{25}$ A detailed description of the SDM-DC intervention can be found in the online supplementary material. The pilot test confirmed that SDM-DC was useful in encounters between individual patients and a dialysis coordinator at a Danish university hospital, but that further research was needed to gain insight into patients' experiences of involvement and the implications for their choice of dialysis mode. ${ }^{10}$

\section{Aim}

The aim of this study was to evaluate the SDM-DC intervention with regard to patients' experience and involvement.

\section{METHODS}

This study is part of a larger project evaluating the SDM-DC complex intervention. ${ }^{26}{ }^{27}$ As recommended for complex interventions, ${ }^{28-30}$ we first conducted a qualitative evaluation. The quantitative evaluation is in review for publication elsewhere. Since October 2016, the intervention has been delivered at four hospitals in Denmark by six different dialysis coordinators. The inclusion criteria for the intervention were adult patients with chronic kidney disease referred to a department of renal medicine with an estimated glomerular filtration rate (eGFR) below $20 \mathrm{~mL} / \mathrm{min}$ measured by a 24 -hour urine test. The exclusion criteria were patients who had decided on palliation, patients with a living donor and a set date for transplantation, and patients not able to participate due to cognitive impairment. The use of an interpreter was not an exclusion criterion.

\section{Patient and public involvement}

Patients and healthcare professionals have been involved in the whole research process ${ }^{31-33}$ through an advisory board consisting of six dialysis coordinators and two patients. The two patients on the board have not been part of the intervention but are part of the target group for it. The first author and the advisory board met every 6 months during the research process. For this study, the advisory board has contributed particularly to the validation of the themes and inspiration for the discussion.

\section{Data collection}

We collected data through individual interviews with patients after they had participated in SDM-DC. We conducted interviews between 1 February 2017 and 8 August 2018. The patients were interviewed consecutively after receiving the intervention. The patients decided on their own where the interview would take place and whether their relatives would participate or not. The first author, who does not perform the intervention, conducted the interviews. The individual interviews were conducted according to Kvale and Brinkmann's guidelines,${ }^{34}$ with a semistructured interview guide. The purpose of the individual interviews was to gain a clear insight into how the patients experienced the impact of SDM-DC on their involvement in the decision-making process. The key elements in the "three-talk model ${ }^{14}$ informed the content of the interview guide, which was structured chronologically around the first talk, the second talk, the third talk and decision support, from initial preferences to informed preferences and the decision. We adapted the interview guide for each interview according to how the patient, prior to the interview, had answered two questionnaires-the Shared Decision-Making Questionnaire ${ }^{35}$ and the Decision Quality Measurement ${ }^{20}$ - not changing the initial questions but making the follow-up questions more specific. During the interviews, the communication skills of mirroring and active listening were used. ${ }^{16} 17$ First, mirroring was used to bring patients' experiences to the forefront. Active listening, such as retelling the patient's story, then allowed patients to adjust their story if they wished. At the end of every interview, the interviewer summarised the patient's story so the patient could comment on this summary. The purpose of the interviews was not to question the decision the patient had made 
or to convey information. One patient was emotionally moved by the interview and was offered a new meeting with the dialysis coordinator.

\section{Data analysis}

To achieve a well-considered and well-documented analysis, we used a four-step systematic text condensation process. ${ }^{36}{ }^{37}$ Systematic text condensation is a descriptive and explorative method for thematic cross-case analysis. During interviews, the first author performed some primary analysis and noted preliminary themes. These preliminary themes were discussed with the third author and the advisory board, which led to some changes. These themes were targeted in subsequent interviews with the following patients. The interviews were recorded and transcribed verbatim prior to data analysis, and the software program NVivo V. $11^{38}$ was used for data management. Various features in NVivo were used to support the different steps of the analysis process, and to ensure that analyses were both systematic and transparent. These features included Coding, Classification and Memos, and also Word Cloud to identify other preliminary themes, Text Search Query to find meaningful units that had been overlooked, and Matrix Coding Query to investigate whether a code could be attributed to some characteristics within the interview situation or interviewee. The first step in the systematic text condensation was naive reading, which was performed to obtain an overview of the data. This was conducted continuously during the interview period. The second step was to identify and sort meaningful units by coding. The third step involved condensation of the meaningful units of interest in accordance with the aim of the study. All references from each source were condensed and written as narratives in the first person and present tense to represent each participant's story in relation to each specific code. The fourth and final step involved synthesising the transcription of each finding. All condensed texts for each finding were aggregated into one text and formulated as narratives in the third person and past tense, including illustrative quotations.

\section{FINDINGS}

The interviews took place between 14 and 42 days after the intervention. Out of 59 patients invited for interviews, 33 accepted the invitation, but 4 of these patients were not able to participate due to their medical condition worsening. Table 1 shows the characteristics of the 29 patients who participated in the interviews side by side with the characteristics of the whole sample. The variation in the sample was close to the total sample for the intervention according to gender, age, hospitals, dialysis coordinators and the choice of dialysis mode.

The interviews lasted on average $50 \mathrm{~min}$, ranging from 26 to $73 \mathrm{~min}$, with an information load of 670 normal pages in total and 23 normal pages on average. Fifteen interviews were conducted at the hospitals and 14 in
Table 1 Participant characteristics*

\begin{tabular}{|c|c|c|}
\hline & $\begin{array}{l}\text { Intervention } \\
\text { sample } \\
(n=349)\end{array}$ & $\begin{array}{l}\text { Interview I } \\
\text { study sample } \\
(\mathrm{n}=29)\end{array}$ \\
\hline & n (\%) & $\mathrm{n}(\%)$ \\
\hline \multicolumn{3}{|l|}{ Sex } \\
\hline Female & $123(35)$ & $8(28)$ \\
\hline Male & $226(65)$ & $21(72)$ \\
\hline \multicolumn{3}{|l|}{ Age (years) } \\
\hline$<50$ & $38(11)$ & $0(0)$ \\
\hline $50-60$ & $45(13)$ & $3(10)$ \\
\hline $60-70$ & $94(27)$ & $9(31)$ \\
\hline $70-80$ & $112(32)$ & $12(42)$ \\
\hline$\geq 80$ & $59(17)$ & $5(17)$ \\
\hline \multicolumn{3}{|l|}{ eGFR (mL/min) } \\
\hline$<10$ & $82(23)$ & $3(10)$ \\
\hline $10-20$ & $244(70)$ & $26(90)$ \\
\hline$\geq 20$ & $23(7)$ & $0(0)$ \\
\hline \multicolumn{3}{|l|}{ Chosen option } \\
\hline Peritoneal dialysis & $228(65)$ & $20(69)$ \\
\hline Home haemodialysis & $26(8)$ & $4(14)$ \\
\hline Hospital haemodialysis & $87(25)$ & $5(17)$ \\
\hline No decision & $8(2)$ & $0(0)$ \\
\hline \multicolumn{3}{|l|}{ Number of meetings } \\
\hline 1 & $90(26)$ & $2(7)$ \\
\hline 2 & $215(62)$ & $17(59)$ \\
\hline 3 & $40(11)$ & $10(34)$ \\
\hline 4 & $4(1)$ & $0(0)$ \\
\hline \multicolumn{3}{|l|}{ Hospitals† } \\
\hline I & $180(52)$ & $12(41)$ \\
\hline II & $53(15)$ & $7(24)$ \\
\hline III & $60(17)$ & $8(28)$ \\
\hline IV & $56(16)$ & $2(7)$ \\
\hline
\end{tabular}

*Data used in this table have been registered by the dialysis coordinators and are consistent with the documentation in patients' electronic health records.

†The roman numerals indicate each of the participating hospitals. eGFR, estimated glomerular filtration rate.

patients' homes. Eight patients chose to participate in the interview together with a spouse, and 21 were on their own. Table 2 gives an overview of the category headings, codes and chosen quotations. In the text, the category headings are underlined, while the codes are in italics.

- The decision was experienced as being their own

This was stated by 28 patients in different ways. Some of the patients stated that they had made their decision together with their relatives; others stated that their relatives had not influenced their decision. Some patients stated that their relatives agreed with their decision. They stated that the healthcare professionals had not made 


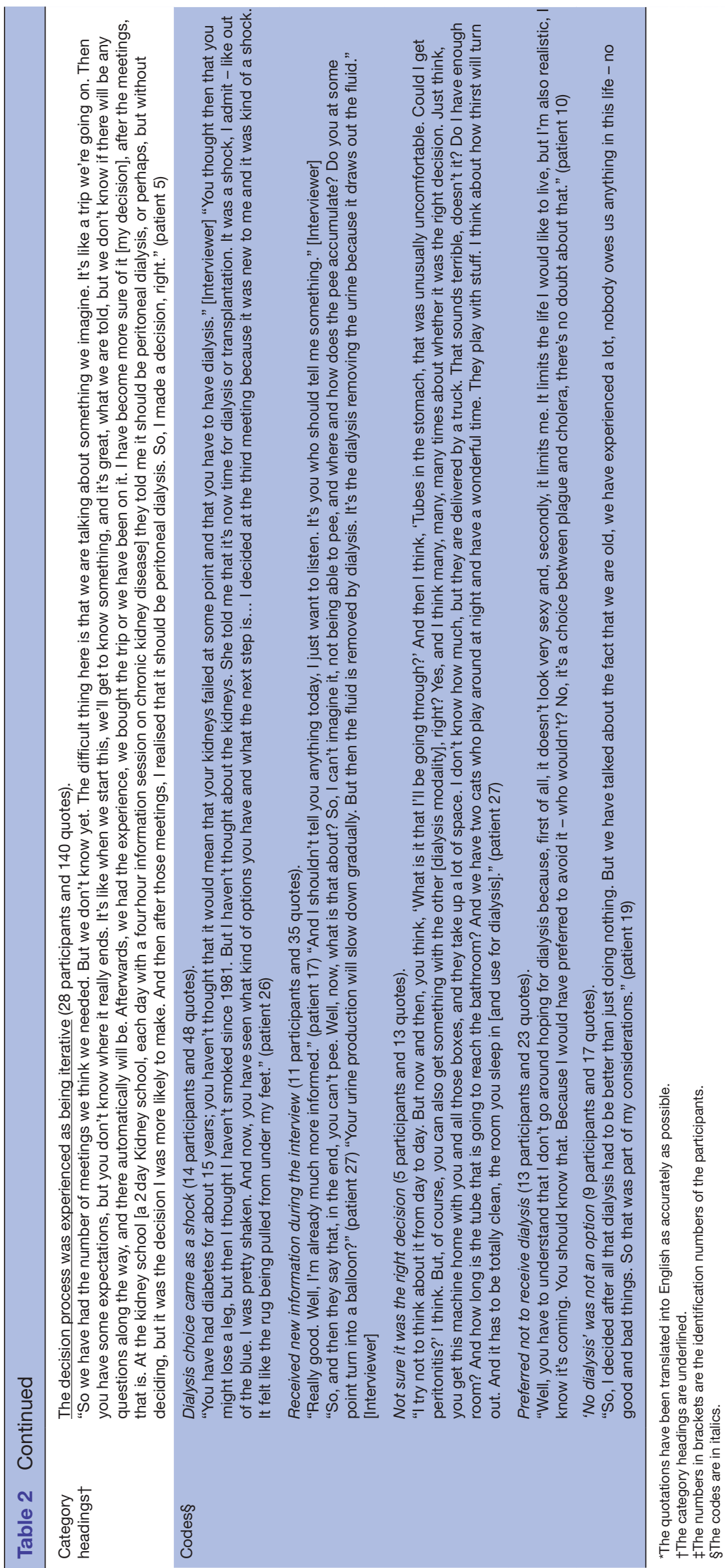


the decision, even though the dialysis coordinator had contributed to the decision process. For several patients, it had been important that the healthcare professionals had confirmed their decision. One patient did not directly express that the decision was his own (patient 2 ). This patient was over the age of 80 , and the focus for his decision process was whether to go on dialysis or not. Several patients stated that it was important that the decision was their own because they thought it made the decision easier to accept. None of the patients experienced being left alone with the decision process.

\section{- Other decisions.}

Most of the patients had lived with disease for a long period. Most of them had never before experienced being involved in a decision about their treatment. Most of the patients felt that no decision had been involved in previous treatments at all. A few patients had experienced participating in a decision about treatment before, but mostly their experience was that the healthcare professionals regarded patient involvement as an unwelcome interference. Such patients wished that these healthcare professionals had invited them to take part in the decision process and communicated some information to them to enable them to participate.

- The meetings contributed to the decision process.

All 29 patients reported that the meetings with the dialysis coordinators had contributed to the decision process and that they would not have been able to make the decision on their own without the meetings. The patients emphasised the relaxed nature of the meetings as being significant. They felt they had time to go into the decision process in depth.

\section{-Questions to and from the patient.}

These were emphasised by most patients as a significant property of the meetings. There was no relation to demographic, gender, age or the dialysis coordinator. Questions to the patients addressed the impact of the decision on their everyday life. The patients experienced these questions as being asked in a nice, easy way. Questions from the patients were concerned with practical issues. The patients felt confident they could ask the same questions several times.

- Accurate information was helpful for the patient.

Some of the patients emphasised that information communicated by the dialysis coordinator had been helpful in the decision process. These patients stated that the information communicated should be detailed, accurate and appropriate to their life, and that information should be repeated. Two patients (patients 2 and 7) expressed that some of the information communicated by the dialysis coordinator had not been helpful; this appeared to be when the dialysis coordinator gave too much information at a single meeting.

- Bringing a relative into the meetings contributed to the decision process.

This was emphasised by most of the patients. They had chosen to bring a relative to be part of the meetings, most often a wife or husband, but in some cases a daughter and son-in-law or a friend. Bringing a relative to the meetings was mentioned as 'a habit'. These patients were used to bringing a relative to important meetings at the hospital and expressed that 'being two' made it possible for them to ask more and different questions. They further emphasised the benefits of there being two people to listen. A few patients (patients 6, 11, 17, 19 and 29) did not bring a relative to the meetings. These patients explained that they did not have a significant other in their lives or that their significant others were too ill to participate in the meetings.

- The decision aid contributed to the decision process.

All 29 patients expressed that they could not have made their decision without help from the decision aid. The patients talked about the PDA as one tool and only mentioned two of the tools within the PDA specifically: the overview of options and the value clarification tool. Some of the patients mentioned the two videos, and they also mentioned other patients, although other patients are not an integrated part of the intervention.

- The overview of options contributed to the decision process.

This was expressed spontaneously by most of the patients. The tool had clarified or confirmed their decision. They had used the tool during the meeting, but also after the meeting and in preparation for the next meeting. Several patients stated that they had saved the tool and continued to use it.

- The value clarification tool contributed to the decision process. Most of the patients stated spontaneously that the value clarification tool was particularly valuable. Several patients indicated specifically that this tool had contributed to the decision process and elaborated that the questions in the tool had enabled them to reflect, in particular the part where they write down pros and cons. Some patients had filled in the tool before the meeting using the value clarification tool, and others received help at the meeting to complete it.

- The videos contributed to the decision process for some patients.

Some patients used positive words in their descriptions of the videos. One patient reported that the videos had helped him change his decision (patient 25), one reported that the videos had removed his concern about dialysis (patient 19), and one that they had provided some concrete visuals of how dialysis takes place (patient 13). Three patients used positive words about the videos but stated explicitly that the videos had not contributed to their decision process (patients 3, 4 and 7). One patient used negative words about the videos (patient 16). This patient had made a decision before seeing the videos and would have preferred them to have a more practical focus.

- Other patients contributed to the decision process sometimes.

A number of patients in the sample met other patients on dialysis. For some of this group, meeting other patients on dialysis contributed to the decision process, but several of these patients (patients 3, 11, 22, 25 and 27) did not choose the same option as the patient they had met. A 


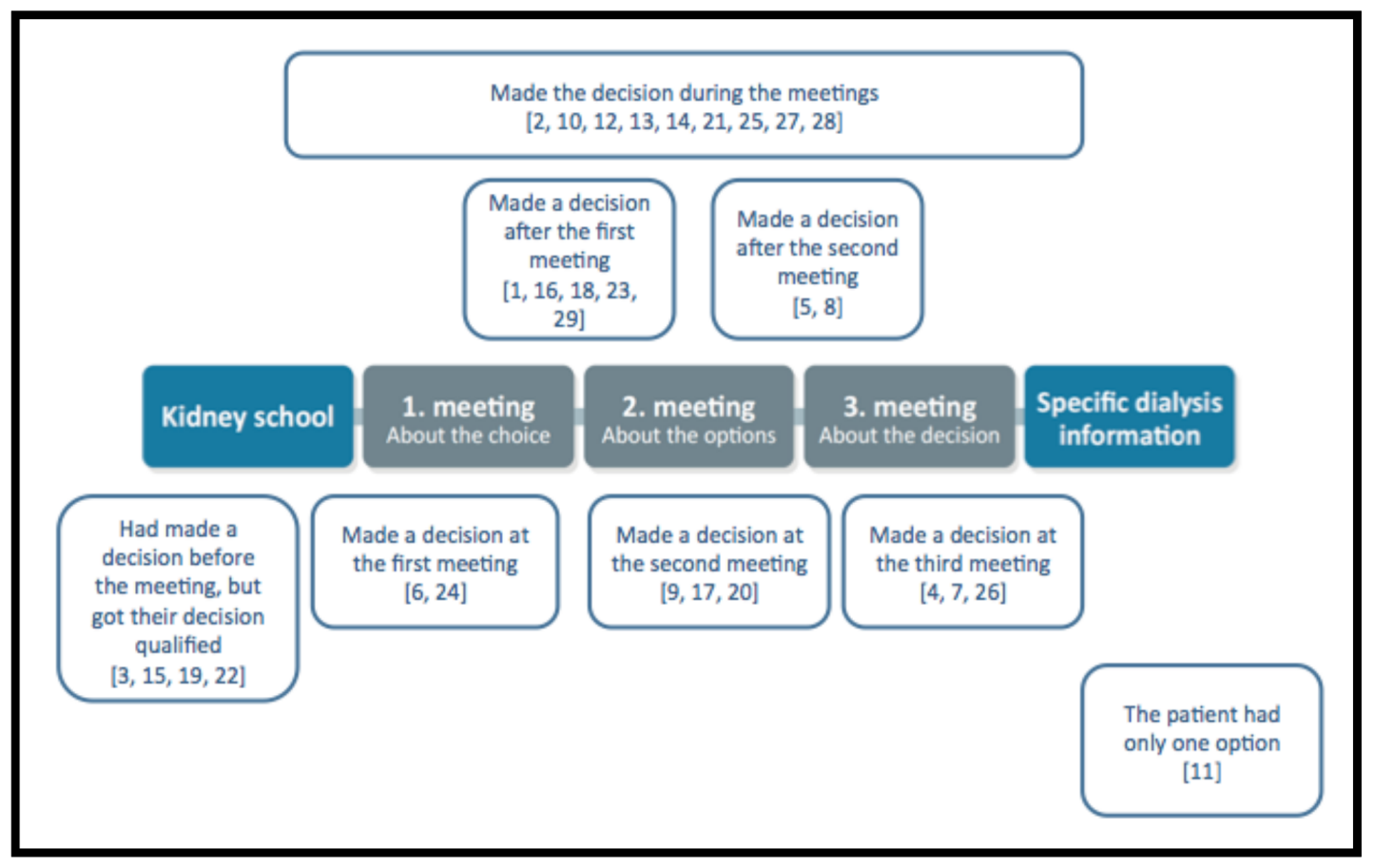

Kidney school: A 2-day school, each day with a four hour information session on chronic kidney disease

Figure 1 Overview of when the patients experienced the decision to be made.

few of the patients did not know why the patient they met had chosen as they had. Other patients contributed to the decision process by making dialysis more concrete and presenting possibilities. For some of the patients, it was scary to meet other patients on dialysis.

- The decision process was experienced as being iterative.

Only one patient did not mention the decision process at all. This patient had only one possible dialysis modality. Four patients stated that they had made their decision before the meetings, but all four had their decision confirmed during the meetings. Nine patients stated that their decision was made during the meetings. One of these patients had made a decision beforehand but changed this during the meetings. Eight patients stated that their decision was made concrete at a meeting. Two patients made their decision at the first meeting, three patients made their decision at the second meeting, and three patients made their decision at the third meeting. Figure 1 gives an overview of when patients felt their decision was made.

Nearly all participants experienced the decision process as iterative. Although they had made a decision, they still needed to confirm this decision, to ask questions and to reconsider it. There was not only a single option suitable for each patient, but several patients decided on one option to start with (plan A) and then had plans B and C.

- Dialysis choice came as a shock.

Dialysis choice came as a shock for half of the patients, although they had been known to the departments of renal medicine for several years. That dialysis could actually be a treatment for them occurred to the patients just before the meetings or during the meetings. Some of the patients knew that dialysis might be an option someday, but they had ignored this knowledge and thought it was not going to happen to them. One of the patients (patient 10) was happy not to have received this knowledge previously, but two of the patients (patients 12 and 23) stated that they would have preferred to have known earlier. One patient (patient 13) stated that he would have preferred to receive this knowledge in a nice, easy way. Surprisingly, no correlation has been found between eGFR and dialysis choice coming as a shock. Rather, it appeared to be experienced as a shock more often by patients at two of the hospitals compared with those at the other two.

- Received new information during the interview.

Some patients received new information about the significance of the decision regarding dialysis modality during the interview. It was not the intention for the interviewer to interact with the intervention, but the patients asked some questions, and the interviewer tried to answer these questions briefly. The information given did not change their decision. One patient had doubts after the interview and needed one extra meeting. This meeting did not change her decision (patient 27).

- Not sure it was the right decision.

This was expressed by five patients. At the same time, they said that there was nothing we could do to make them more certain about the decision. They stated that they thought they would feel certainty when they first started dialysis.

- Preferred not to receive dialysis. 
This was expressed by some of the patients. They preferred not to receive any dialysis treatment and characterised the options as a choice between two evils associated with various problems and a loss of their present lifestyle. These participants still hoped to recover and no longer be in need of dialysis.

- 'No dialysis' was not an option.

This was considered by some of the patients. This code was mainly found among patients over the age of 80 years. The patients aged over 80 felt they still had something to live for. Some stated that if their spouse died, they would reconsider their decision and perhaps choose 'no dialysis'. Most of the patients stated that they had considered these issues on their own, but they had shared their consideration with the healthcare professionals.

\section{DISCUSSION}

In summary, the patients experienced the decision as being their own, but both the meetings and the PDA had contributed to the decision-making process. They experienced the decision-making process as iterative. The discussion is divided into three sections. The first two sections correspond to the aim, and the last section focuses on the limitations of the study.

\section{How did the patients experience the SDM-DC intervention in terms of their involvement?}

The purpose of the intervention was to involve patients in the decision-making process. The decision was experienced as being their own was a significant finding, which demonstrates that the patients experienced SDM-DC as involving them in the decision-making process. The SDM-DC pilot test predicted this finding, because some of the patients did not experience the decision as a shared decision, but their own decision. ${ }^{10}$ Due to the age of the patient group, this finding was surprising when compared with a study focusing on the involvement of the over-65 age group. ${ }^{39}$ That study showed that many patients were not involved in the decision-making process about dialysis choice, but the patients who were involved were more satisfied with their dialysis modality. ${ }^{39}$ We found the patients experienced the decision process as iterative. SDM-DC is based on the 'three-talk model' by Elwyn et al. ${ }^{14}$ The simple version of the 'three-talk model' presents the SDM process as linear, suggesting that patients go into the decision-making process without any decisions and complete the process with a decision. In 2017, the 'three-talk model' was updated and is no longer presented as a linear model, but a circular one. ${ }^{40}$ Both models have their advantages. In clinical practice, it is easier to implement an intervention based on the linear model with clear progression through the process. Nonetheless, it is worth noting that SDM-DC seems to be the first intervention to apply the linear version of the 'three-talk model'. ${ }^{40}$ The model has been cited a number of times elsewhere but only for presentations, workshops and training programmes. A Canadian study found five phases in the decision-making process regarding dialysis choice: (1) progress towards acceptance to be dialysed; (2) receive information; (3) take some time for personal reflection; (4) seek the opinion and support of others; and (5) re-evaluate one's choice. ${ }^{41}$ The development of SDM-DC was not based on this framework, but our evaluation showed that most of these phases have been met by the intervention.

\section{How did the patients experience the SDM-DC intervention?}

The patients highlighted two important elements of the meetings: (1) questions to and from the patient; and (2) the dialysis coordinator providing accurate information about the options. The fact that daily life with dialysis needs to be described as concretely as possible has been documented elsewhere. ${ }^{42}$ The patients experienced the participation of their relatives in the meetings as an advantage. This finding is in accordance with a study of the perspective of the relative, showing that relatives felt involved in the decision-making process and that they had an important supportive role. ${ }^{43}$ The dialysis coordinator provided decision coaching as part of the SDM process. The definition of decision coaching is 'individualized, nondirective facilitation of patient preparation for shared decision-making. ${ }^{44}$ In spite of this, the decision was made together with the dialysis coordinators at the meetings and not afterwards with the physician. Decision coaching has, in other studies, been shown especially to improve the patient's knowledge and involvement in decision-making. ${ }^{44}$ The whole of the 'Dialysis Choice' PDA contributed to the decision-making process, but the patients identified the overview of options and the value clarification tool as being particularly helpful. An Option Grid is a specific type of overview of options, and research has shown that, for some health decisions, an Option Grid supports patients in the decision-making process. ${ }^{45}$ From a healthcare perspective, the Option Grid has been found to be easy to use to facilitate patient involvement in the decision-making process. ${ }^{46}$ In general, Option Grids have proven beneficial for sharing information but less useful for value clarification. ${ }^{47}$ In the Cochrane review of PDAs, value clarification is defined as an important part of a PDA and SDM. ${ }^{13}$ The combination of the overview of options and the value clarification tool appears to be a good one. In the development of our intervention and the PDA, we tried to meet all the decision needs described for this patient population, ${ }^{11} 4148-50$ but this study added two more decisional needs for this patient population, namely that the decision came as a shock to the patient and that there is not only one choice but plans A, B and C. These decisional needs should be implemented into an SDM intervention for dialysis choice. The impact of stories on patient decision-making has been unclear. ${ }^{51}$ The patients in our study felt the videos were not as unequivocally positive as the decision aid, nor was meeting other patients on dialysis an unequivocally positive finding. Sometimes, other patients contributed to the decision-making process to a certain extent. The 
use of narratives in decision aids has been a focus in the International Patient Decision Aids Standards collaboration since the beginning. ${ }^{20}$ An experimental study has shown that patients are more likely to choose a dialysis modality presented by a patient rather than a healthcare professional, which is why caution has been recommended in the use of patient stories. ${ }^{49}$ It seems that the patients in our study used the videos and other patients more as inspiration and less as direction, thus complying with the purpose of SDM to establish a decision process based not on uninformed preferences but on informed preferences. ${ }^{14}$ How the intervention has contributed to this needs to be investigated further.

\section{Limitations}

This study has some limitations. For a qualitative evaluation, 29 patients is a relatively large number of participants. This number was chosen to give the right level of information power, ${ }^{52}$ because the intervention was performed at four different hospitals, by six different dialysis coordinators, and the patients had to decide between different options. Only Caucasian patients were included, and the findings are therefore limited to ethnic Danish patients. If we had included some ethnically non-Danish patients, the findings could have taken other directions. This is indicated by a study showing that Japanese patients make decisions that are more consistent with their network's wishes and preferences. ${ }^{53}$ One of the developers of the intervention carried out the interviews in our study, and this is mentioned by Malterud ${ }^{36}$ as a point to pay attention to. We managed this challenge in various ways: (1) the interviewer did not perform the intervention; (2) the patients did not know that the interviewer had developed the intervention; and (3) the interview findings were discussed with the advisory board. Furthermore, the patients expressed criticism of the intervention during the interviews. The interviews were performed at least 2 weeks after the intervention. Thus, some memory failure may have occurred since patients with an eGFR below $20 \mathrm{~mL} / \mathrm{min}$ may have cognitive deficit and short memory ${ }^{54}$ We assume that the patients have a better memory of the last meeting than the first meeting. We do not yet know the extent to which the intervention has been performed as intended. In the sample, we found two patients who had filled out the value clarification tool, but the dialysis coordinators had not used the homework during the meetings. The dialysis coordinators, who are part of the advisory group, later explained that they found the value clarification tool difficult to use in the beginning.

\section{CONCLUSION}

The patients experienced SDM-DC as involving them in their choice of dialysis modality. Due to the iterative properties of the decision-making process, an SDM intervention for dialysis choice needs to be adapted to the needs of individual patients. The active mechanisms of the meetings with the dialysis coordinator were (1) questions to and from the patient; and (2) the dialysis coordinator providing accurate information about the options. The overview of options and the value clarification tool in the decision aid particularly contributed to the decision-making process based on informed preferences.

Acknowledgements The authors thank the departments of renal medicine at the four participating hospitals- the hospitals in Hillerød, Sønderborg, Holstebro and Aarhus - and especially the dialysis coordinators who provided the interventions. The authors thank the advisory board and the patients who participated in this study.

Contributors JF designed the project, collected and analysed the data, and drafted the final manuscript. JDJ and KL provided academic supervision, helped to draft the manuscript, and read and approved the final manuscript.

Funding The project has received funding from the Danish Health Authority, the Danish Kidney Association and the Danish Nurses Organisation.

Competing interests None declared.

Patient consent for publication Not required.

Ethics approval Participation in the intervention was based on consent for care and treatment. According to Danish legislation, this type of research is exempted from ethical approval. The Danish Data Protection Agency (jr. 1-16-02-456-16) approved the data management. A third person obtained written consent from patients before their participation in the interviews.

Provenance and peer review Not commissioned; externally peer reviewed.

Data availability statement No data are available.

Open access This is an open access article distributed in accordance with the Creative Commons Attribution Non Commercial (CC BY-NC 4.0) license, which permits others to distribute, remix, adapt, build upon this work non-commercially, and license their derivative works on different terms, provided the original work is properly cited, appropriate credit is given, any changes made indicated, and the use is non-commercial. See: http://creativecommons.org/licenses/by-nc/4.0/.

ORCID iD

Jeanette Finderup http://orcid.org/0000-0003-2646-0227

\section{REFERENCES}

1 Korevaar JC, Feith GW, Dekker FW, et al. Effect of starting with hemodialysis compared with peritoneal dialysis in patients new on dialysis treatment: a randomized controlled trial. Kidney Int 2003;64:2222-8.

2 Wong B, Ravani P, Oliver MJ, et al. Comparison of Patient Survival Between Hemodialysis and Peritoneal Dialysis Among Patients Eligible for Both Modalities. American Journal of Kidney Diseases 2018;71:344-51.

3 Covic A, Bammens B, Lobbedez T, et al. Educating end-stage renal disease patients on dialysis modality selection: clinical advice from the European renal best practice (ERBP) Advisory board. Nephrology Dialysis Transplantation 2010;25:1757-9.

4 Mehrotra R. Comparing outcomes of hemodialysis and peritoneal dialysis patients: consider the pitfalls. Contrib Nephrol 2012;178:30-4.

5 Stack AG, Martin DR. Association of patient autonomy with increased transplantation and survival among new dialysis patients in the United States. Am J Kidney Dis 2005;45:730-42.

6 King K. Patients' perspective of factors affecting modality selection: a national kidney Foundation patient survey. Adv Ren Replace Ther 2000;7:261-8.

7 Song M-K, Lin F-C, Gilet CA, et al. Patient perspectives on informed decision-making surrounding dialysis initiation. Nephrol Dial Transplant

8 Song M-K, Ward SE. The extent of informed decision-making about starting dialysis: does patients' age matter? J Nephrol 2014;27:571-6.

9 Durand M-A, Bekker HL, Casula A, et al. Can we routinely measure patient involvement in treatment decision-making in chronic kidney care? A service evaluation in 27 renal units in the UK. Clin Kidney $J$ 2016;9:252-9. 
10 Finderup J, Jensen JKD, Lomborg K. Developing and pilot testing a shared decision-making intervention for dialysis choice. J Ren Care 2018;44:152-61.

11 Erlang AS, Nielsen $\mathrm{IH}$, Hansen $\mathrm{HOB}$, et al. Patients experiences of involvement in choice of dialysis mode. J Ren Care 2015;41:260-7.

12 Légaré F, Adekpedjou R, Stacey D, et al. Interventions for increasing the use of shared decision making by healthcare professionals. Cochrane Syst Rev 2018;2.

13 Stacey D, Légaré F, Lewis K, et al. Decision AIDS for people facing health treatment or screening decisions. Cochrane Database Syst Rev 2017;19.

14 Elwyn G, Frosch D, Thomson R, et al. Shared decision making: a model for clinical practice. J Gen Intern Med 2012;27:1361-7.

15 Noar SM, Benac CN, Harris MS. Does tailoring matter? Meta-analytic review of tailored print health behavior change interventions. Psychol Bull 2007;133:673-93.

16 Clabby J, O'Connor R. Teaching learners to use mirroring: rapport lessons from neurolinguistic programming. Fam Med 2004;36:541-3.

17 Gordon TKB. Parent education: problems, conflicts, solutions. Borgen, 1990.

18 Steinberg JM. Aktivt verdivalg. Meninger OG handlinger. en pedagogisk metodikk. 3rd ed. Aventura, 1986.

19 Coulter A, Stilwell D, Kryworuchko J, et al. A systematic development process for patient decision AIDS. BMC Med Inform Decis Mak 2013;13 Suppl 2:S2.

20 Prichard A, Thomas N. The option grid: a shared decision-making tool for renal patients. Journal of Renal Nursing 2013;5:6-11.

21 Fortnum D, Grennan K, Smolonogov T. End-stage kidney disease patient evaluation of the Australian 'My Kidneys, My Choice' decision aid. Clin Kidney J 2015;8:469-75.

22 Winterbottom AE, Gavaruzzi T, Mooney A, et al. Patient acceptability of the Yorkshire dialysis decision aid (YoDDA) booklet: a prospective Non-Randomized comparison study across 6 predialysis services. Perit Dial Int 2016;36:374-81.

23 Elwyn G, O'Connor A, Stacey D, et al. Developing a quality criteria framework for patient decision AIDS: online international Delphi consensus process. BMJ 2006;333:417-9.

24 O'Connor AM, Jacobsen MJ, Stacey D. An evidence-based approach to managing women's decisional conflict. J Obstet Gynecol Neonatal Nurs 2002;31:570-81.

25 Finderup J, Baker H. Ottawa personal decision guide, Danish version (OPDG-Danish), 2016. Available: https://decisionaid.ohri.ca/docs/ das/OPDG-Danish.pdf

26 Craig P, Dieppe P, Macintyre S, et al. Developing and evaluating complex interventions: the new medical Research Council guidance. BMJ 2008;337.

27 Richards DA, Hallberg IR. Complex interventions in health: an overview of research methods. Routledge, 2015.

28 Craig P, Petticrew M. Developing and evaluating complex interventions: reflections on the 2008 MRC guidance. Int J Nurs Stud 2013;50:585-7

29 Ludvigsen MS, Meyer G, Hall E, et al. Development of clinically meaningful complex interventions - the contribution of qualitative research. Pflege 2013;26:207-14.

30 Thirsk LM, Clark AM. Using qualitative research for complex interventions: the contributions of hermeneutics. Int J Qual 2017;16:1-10.

31 Staniszewska S, Brett J, Simera I, et al. GRIPP2 reporting checklists: tools to improve reporting of patient and public involvement in research. BMJ 2017;358:j3453.

32 Domecq JP, Prutsky G, Elraiyah T, et al. Patient engagement in research: a systematic review. BMC Health Serv Res 2014;14:89.
33 Brett J, Staniszewska S, Mockford C, et al. Mapping the impact of patient and public involvement on health and social care research: a systematic review. Health Expect 2014;17:637-50.

34 Kvale S, Brinkmann S. Interviews: learning the craft of qualitative research interviewing. 2nd ed. Sage Publications, 2009.

35 Kriston L, Scholl I, Hölzel L, et al. The 9-item shared decision making questionnaire (SDM-Q-9). development and psychometric properties in a primary care sample. Patient Educ Couns 2010;80:94-9.

36 Malterud K. Kvalitative forskningsmetoder for medisin OG helsefag. 4th ed. Universitetsforlaget, 2017.

37 Malterud K. Systematic text condensation: a strategy for qualitative analysis. Scand J Public Health 2012;40:795-805.

38 QSR International Pty Ltd. NVivo qualitative data analysis software 2015.

39 Ladin K, Lin N, Hahn E, et al. Engagement in decision-making and patient satisfaction: a qualitative study of older patients' perceptions of dialysis initiation and modality decisions. Nephrol Dial Transplant 2017;32:1394-401.

40 Elwyn G, Durand MA, Song J, et al. A three-talk model for shared decision making: multistage consultation process. BMJ 2017;359.

41 Loiselle M-C, Michaud C, O'Connor A. Decisional needs assessment to help patients with advanced chronic kidney disease make better dialysis choices. Nephrol Nurs J 2016;43:463-93.

42 Thomas N, Jenkins K, McManus B, et al. The experience of older people in the shared decision-making process in advanced kidney care. Biomed Res Int 2016;2016:1-8.

43 de Rosenroll A, Higuchi KS, Dutton KS, et al. Perspectives of significant others in dialysis modality decision-making: a qualitative study. Cannt J 2013;23:17-24.

44 Stacey D, Kryworuchko J, Bennett C, et al. Decision coaching to prepare patients for making health decisions: a systematic review of decision coaching in trials of patient decision AIDS. Med Decis Making 2012;32:E22-33.

45 Scalia P, Durand M-A, Kremer J, et al. Online, interactive option grid patient decision AIDS and their effect on user preferences. Med Decis Making 2018;38:56-68.

46 Elwyn G, Lloyd A, Joseph-Williams N, et al. Option grids: shared decision making made easier. Patient Educ Couns 2013;90:207-12.

47 Tsulukidze M, Grande SW, Gionfriddo MR. Assessing option Grid $®$ practicability and feasibility for facilitating shared decision making: an exploratory study. Patient Educ Couns 2015;98:871-7.

48 Murray MA, Brunier G, Chung JO, et al. A systematic review of factors influencing decision-making in adults living with chronic kidney disease. Patient Educ Couns 2009;76:149-58.

49 Winterbottom AE, Bekker HL, Conner M, et al. Patient stories about their dialysis experience biases others' choices regardless of doctor's advice: an experimental study. Nephrol Dial Transplant 2012;27:325-31.

50 Winterbottom A, Bekker HL, Conner M, et al. Choosing dialysis modality: decision making in a chronic illness context. Health Expect 2014;17:710-23.

51 Khangura S, Bennett C, Stacey D, et al. Personal stories in publicly available patient decision AIDS. Patient Educ Couns 2008;73:456-64.

52 Malterud K, Siersma VD, Guassora AD. Sample size in qualitative interview studies: guided by information power. Qual Health Res 2016;26:1753-60.

53 Nakamura-Taira N, Muranaka Y, Miwa M, et al. Views of Japanese patients on the advantages and disadvantages of hemodialysis and peritoneal dialysis. Int Urol Nephrol 2013;45:1145-58.

54 Elias MF, Dore GA, Davey A. Kidney disease and cognitive function. Contrib Nephrol 2013;179:42-57. 